\title{
A “GUERRA DOS DEUSES” NO BRASIL: DA TEOLOGIA DA LIBERTAÇÃO À ELEIÇÃO DE BOLSONARO*
}

\author{
Geoffrey Pleyers ${ }^{1}$
}

\begin{abstract}
RESUMO: A mudança de um governo progressista para um país liderado por um presidente de extrema-direita em apenas alguns anos também é resultado de duas grandes mudanças que ocorreram nos anos 1980: a virada conservadora na Igreja Católica - e seus ataques à teologia e às práticas da libertação - e a ascensão concomitante de igrejas neopentecostais conservadoras. O impacto dessas mudanças foi pouco visível na arena política brasileira nas décadas seguintes, quando ativistas formados nas Comunidades Eclesiais de Base mantiveram seus compromissos progressivos em organizações, partidos e movimentos sociais estabelecidos. Em longo prazo, deixou um vácuo, logo preenchido pelas igrejas conservadoras neopentecostais, que atuaram como grandes incubadoras de militantes e eleitores de Jair Bolsonaro.
\end{abstract}

Palavras-chave: Teologia da Libertação. Religião. Movimentos sociais. Igrejas neopentecostais. Bolsonaro.

\section{THE “WAR OF GODS” IN BRAZIL: FROM LIBERATION THEOLOGY TO BOLSONARO'S ELECTION}

\begin{abstract}
The change from a progressive government to a country led by a far-right president in just a few years finds one of its roots in two major changes that took place in the 1980s: the conservative turn in the Catholic Church - and its attacks on liberation theology and practices -, and the concomitant rise of conservative neo-Pentecostal churches. The impact of these changes was little visible in the Brazilian political arena in the following decades, when activists formed in the Base Ecclesial Communities established organizations, parties and social movements. In the long term, the vacuum left was soon filled by the neoPentecostal conservative churches, which acted as a great incubator of militants and voters of Jair Bolsonaro.
\end{abstract}

Keywords: Liberation Theology. Religion. Social movements. Neo-Pentecostal churches. Bolsonaro.

1.University of Louvain - Louvain-la-Neuve, Bélgica. E-mail: geoffrey.pleyers@uclouvain.be

*Versão em português a cargo de Gabriel Guerra, Luisa Souto, Flavia Faria e Brena de Almeida 


\title{
LA “GUERRA DE LOS DIOSES EN BRASIL”: DE LA TEOLOGÍA DE LA LIBERACIÓN A ELECCIÓN DE BOLSONARO
}

\begin{abstract}
RESUMEN: El cambio de un gobierno progresista a un país dirigido por un presidente de extrema derecha en pocos años es uno de los resultados de dos cambios importantes que tuvieron lugar en la década de 1980: el giro conservador de la Iglesia Católica - y sus ataques a la teología e a las prácticas de la liberación, - y el desarrollo concomitante de las iglesias conservadoras neo-pentecostales. El impacto de estos cambios fue poco visible en el ámbito político brasileño en las décadas siguientes, cuando los activistas formados en las Comunidades Eclesiales de Base mantuvieron sus compromisos progresistas con las organizaciones, partidos y movimientos sociales establecidos. Sin embargo, a largo plazo, dejó un vacío, que pronto fue llenado por las iglesias conservadoras neopentecostales, que actuaron como una gran incubadora de militantes y votantes de Jair Bolsonaro.
\end{abstract}

Palabras-clave: Teología de la Liberación. Movimientos sociales. Iglesias neopentecostales. Bolsonaro.

\section{Introdução}

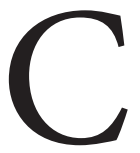

omo o Brasil passou, em apenas alguns anos, de um governo progressista e aberto ao mundo a um país liderado por um presidente de extrema direita? Essa é uma pergunta que inquieta o mundo. Os pesquisadores têm apontado múltiplos fatores: a crise econômica, os escândalos de corrupção, as campanhas midiáticas contra o Partido dos Trabalhadores (PT), o uso eficaz das redes sociais por parte de atores reacionários, a ação de atores ultraliberais, alguns apoiados pelas redes de "think thanks" estrangeiros (AMARAL, 2016) e a crescente polarização da sociedade (BRINGEL; PLEYERS, 2019). Cada um desses fatores desempenhou um papel nessa rápida transformação. Há outro, porém, que se inscreve em longo prazo e é preciso integrar para a compreensão da sociedade brasileira e do sucesso eleitoral de Bolsonaro: a abrangência das transformações no campo religioso no Brasil durante as últimas quatro décadas.

De fato, não há como entender o Brasil contemporâneo e suas mudanças radicais no campo político sem levar em consideração uma mudança no campo religioso quase tão rápida quanto a que aconteceu nos anos 1980, quando se iniciaram dois processos concomitantes: por um lado, o declínio da influência dos católicos progressistas, os quais foram terreno fértil para organizações e movimentos progressistas que transformaram o Brasil nos anos 2000; por outro, a influência política, social e cultural crescente das correntes religiosas conservadoras e, em particular, das igrejas neopentecostais.

Isso está longe de ser algo novo. A religião desempenha um papel na política na maioria dos países da América do Sul. O espaço político do continente tem sido "a longo prazo, um dos espaços privilegiados de ação de grupos e atores religiosos em suas estratégias de construção de identidade e posicionamento institucional" (ESQUIVEL; TONIOL, 2018, p. 475). Ainda assim, chamam a atenção, no Brasil, a dimensão e a velocidade da evolução do panorama político-religioso, bem como a amplitude do protagonismo político de um determinado setor dos evangélicos, em particular entre os fieis das igrejas neopentecostais.

Em 1980, a população brasileira tinha por extração católica $89 \%$ e era um dos principais espaços do cristianismo progressista. No último censo disponível (2016), a população que se identificava 
como católica caiu para 50\%. A proporção dos "evangélicos históricos" se manteve estável ao longo dos últimos 40 anos: 6,6\% em 1980 e 7\% em 2016 (DATAFOLHA, 2016). Enquanto isso, o número de fiéis das igrejas neopentecostais conservadoras aumentou com muita intensidade. Quase inexistente no Brasil em 1980, segundo dados de 2016 do Datafolha, pois representavam 22\% da população nacional.

Sem dúvida, seria um erro considerar que se trata de uma batalha entre católicos progressistas e neopentecostais reacionários. A "guerra dos deuses", para fazer referência novamente ao livro de Löwy (1997), acontece entre correntes conservadoras e progressistas dentro de cada religião. De fato, o giro reacionário da Igreja Católica, encarnado por João Paulo II, nos anos 1980, foi um fator determinante. Ao atacar a Teologia da Libertação e as Comunidades Eclesiais de Base (CEB), particularmente dinâmicas durante as décadas de 1970 e 1980 nas favelas e nos bairros da classe trabalhadora no Brasil (SINGER; BRANT, 1980), tal giro fez com que ambas essas organizações interrompessem o acúmulo da cultura militante e a formação dos atores progressistas que vinham transformando esses lugares. Deixaram, assim, um enorme espaço de atuação para igrejas neopentecostais conservadoras nesses ambientes, os quais se tornaram, por sua vez, sementes de uma nova cultura política e espaços de recrutamento de ativistas e eleitores de Jair Bolsonaro.

De modo a discutir essas mudanças, a primeira parte deste artigo revisa brevemente as principais teses do cristianismo da libertação e enfatiza sua importância como espaço produtivo para militância e fértil ambiente de produção de uma cultura política que transformou o Brasil na segunda metade do século XX, influenciando fortemente a esquerda emergente na redemocratização. A segunda parte é dedicada à mudança conservadora ocorrida durante o pontificado de João Paulo II e aos seus impactos. A terceira parte deste artigo se concentra na crescente influência dos evangélicos conservadores no campo político brasileiro. Essa rápida evolução se beneficiou, notadamente, de afinidades eletivas com a política populista que domina o Brasil hoje, como mostra a quarta e última parte do texto. As considerações finais, por sua vez, destacam os aprendizados que podem ser assimilados pela sociologia dos movimentos sociais a partir dessa análise do vínculo entre movimentos religiosos e políticos no Brasil, antes de invocar batalhas futuras.

\section{O Cristianismo da Libertação: Espaço Fecundo de Militantes Progressistas}

\section{O Cristianismo da Libertação no Brasil}

O Brasil é considerado hoje um terreno de predileção das igrejas neopentecostais. No entanto, há apenas trinta anos, o país era majoritariamente católico e a Teologia da Libertação e o catolicismo progressista eram particularmente influentes em uma parte do seio da hierarquia da Igreja e da sociedade.

O "cristianismo da libertação" é uma cultura religiosa e política, além de um movimento social que possui uma visão do mundo e uma leitura das escrituras que busca tornar os pobres e oprimidos os atores de sua própria emancipação contra um sistema que os oprime. O sociólogo brasileiro Löwy (1997) forjou esse conceito para destacar que o movimento era mais amplo e anterior à Teologia da Libertação, a qual se tornou sua forma mais conhecida no mundo acadêmico. O cristianismo da libertação emergiu em diferentes países da América Latina em meados do século XX a partir do encontro e da reunião de redes religiosas progressistas (católicos e protestantes) com atores e movimentos populares do continente (indígenas ${ }^{1}$, operários, camponeses, trabalhadores urbanos, estudantes...). 
Assim definido, o movimento do cristianismo da libertação é anterior à formalização da Teologia da Libertação (GUTIÉRREZ, 1971). No Brasil, o protagonismo da Ação Católica, que teve início em 1935, e das juventudes católicas carregou princípios e valores da resistência à Ditadura. Portanto, mais do que ponto de partida para reformas, o Segundo Concílio do Vaticano (1962-1965) foi considerado, pelos católicos progressistas da América Latina, um incentivo à libertação. A "preferência pelos pobres" da Teologia da Libertação foi sustentada por parte da hierarquia da Igreja Católica no continente e implementada pela Conferência Latino-americana de Bispos desde a sua criação, em 1955 (PROAÑO, 1977; HOUTART, 1986).

Para esses cristãos engajados, a caridade não é suficiente. O “amor eficaz" (TORRES, 1970) exige lutar contra as causas da pobreza. Isso implica, em si, entender melhor essas causas. Os atores do cristianismo da libertação expressam, por isso, um grande interesse pelas ciências sociais, vistas com suspeita pela Igreja Católica até a década de 1960 (HOUTART, 2018). Na América Latina, da década de 1960 à de 1980, o marxismo influenciou muito as ciências sociais. A conhecida sentença do cardeal brasileiro Dom Helder Câmara, no início dos anos 1980, resume a situação: "Quando dou comida aos pobres, me chamam de santo. Quando pergunto por que eles são pobres, chamam-me de comunista."

Sem nunca ter sido dominante, o cristianismo da libertação foi muito presente na Igreja Católica brasileira desde os anos 1950, pois era mobilizado por CEB, pastorais operárias, parte da hierarquia católica e alguns teólogos brasileiros, como Frei Betto e os irmãos Leonardo e Clodovis Boff. Inicialmente, a hierarquia católica brasileira apoiou o regime militar estabelecido em 1964. Entretanto, após a eliminação da esquerda clandestina, na década de 1970, a Igreja Católica "apareceu aos olhos da sociedade civil e dos próprios militares como o principal adversário do estado autoritário" (LÖWY, 1997, p. 128). Logo, os principais atores da igreja brasileira assinam textos progressistas, críticos e até radicais contra o regime militar. O documento final da conferência dos bispos do Nordeste e do Centro-Oeste, em 1973, concluiu, a título de exemplo dessa radicalidade, assim: “O capitalismo deve ser derrotado: é o mal maior, o pecado acumulado, a raiz podre, a árvore que produz todas esses frutos que nós conhecemos tão bem: pobreza, fome, doença, morte" (LÖWY, 1997, p. 111).

As pastorais operárias e as CEB estão no coração do cristianismo da libertação no Brasil. No início dos anos 1980, o Brasil era o país que mais contava com CEB: eram mais de 50.000 (CAMARGO et al., 1980, p. 62) e cada uma delas reunia em torno de uma dezena a uma centena de famílias. Eram grupos de vizinhos, de funcionamento relativamente horizontal, os quais liam e discutiam as escrituras a partir de sua realidade cotidiana e da situação social de seu país, desenvolvendo ações de caridade e de solidariedade (BURDICK, 1996). Ao inserir o evangelho na realidade concreta de suas vidas, essas comunidades eram instadas "a criar novas formas de vida e, em um esforço conjunto, a inventar novos tipos de comunidades abertas, comprometidas e fraternas” (BARREIRO, 1982, p. 1). A dimensão comunitária era central nas CEB (PROAÑO, 1977), a qual atraá muitas famílias de migrantes das zonas rurais que chegavam em massa às cidades brasileiras, estimuladas pela rápida industrialização do país, e se instalavam nas periferias.

\section{Um Viveiro de Militância}

Formado no contato com movimentos populares, o cristianismo da libertação, em particular as $\mathrm{CEB}$, configurou a essência de uma nova cultura política e uma das principais inspirações para a retomada e o renascimento de movimentos sociais, sindicatos e partidos populares no Brasil, após a pesada repressão à esquerda brasileira levada à cabo pelo regime militar (SADER, 1988). 
As CEB eram grupos de formação religiosa, mas também social. Nelas, os participantes discutiam as escrituras sagradas, mas também refletiam sobre sua vida cotidiana e as injustiças presentes nela. "Uma CEB é o local onde você toma consciência do porquê o ônibus é como é, do porquê não há esgoto, do porquê o salário é o que é. E essa reflexão é sistemática” (SINGER; BRANT, 1980). Nas CEB, a pedagogia de Freire (1967) era muito presente e muitas comunidades tornaram-se verdadeiros grupos de educação popular. Encontros regulares formaram agentes para a discussão e a argumentação, para organização coletiva e a tomada de decisões em grupo. A valorização da experiência e da autonomia era uma questão central para os movimentos (SADER, 1988). Esses cristãos seguidores da Teologia da Libertação pregavam relações mais horizontais no seio da igreja, assim como nos movimentos que eles fundaram. O livro de Boff (1981), intitulado Church, Charisma and Power (Igreja, Carisma e Poder) , desafiou a hierarquia da Igreja e o estilo romano-imperial e carismático de organização do poder. Sem dúvida, esses atores do cristianismo da libertação contribuíram para uma renovação da esquerda, marcada por uma ruptura com as posturas "de vanguarda de esquerda de diversos intelectuais engajados e de marxistas teóricos sem prática” (FOLLMANN, 1994), assim como da Igreja Católica distante das pessoas e do povo.

Uma das especificidades do cristianismo da libertação, em comparação com projetos como a democracia cristã, é a afirmação da autonomia dos movimentos políticos e sociais. No lugar de organizações ou partidos cristãos, ele promove a participação de cristãos em movimentos e/ou partidos seculares (GUTIÉRREZ, 1979, p. 187). Esse novo catolicismo progressista tornou-se importante espaço para ativistas de movimentos, sindicatos e partidos laicos. Durante os últimos anos da ditadura militar, esses militantes se engajaram intensamente na criação dos então "novos movimentos sociais", contribuindo para ela (SADER, 1988). Entre esses estavam diferentes movimentos urbanos (KOWARICK, 1986), o Movimento dos Trabalhadores Rurais sem Terra (MST) (MENEZES NETO, 2007; BLEIL 2012), a Central Única dos Trabalhadores (CUT) - principal central sindical brasileira - e o PT.

Entre os participantes dos encontros nacionais das CEB, em 1981 e 1983, aqueles que haviam se engajado politicamente faziam parte do PT: 66\%, em 1981, e, depois, 67\%, em 1983 (GALLETTA; DOS SANTOS, 1986 apud FOLLMANN, 1994). Uma pesquisa realizada no Rio Grande do Sul, em 1992, mostrou que 69,4\% dos jovens que se declararam favoráveis ao PT afirmaram sê-lo em virtude de suas convicções religiosas (FOLLMANN, 1994, p. 488). O próprio ex-presidente Lula é até hoje membro de uma pastoral operária, como vários outros fundadores da CUT e do PT.

Os cristãos militantes engajados no PT, entrevistados no fim dos anos 1980 e início dos anos 1990, expressaram valores semelhantes aos jovens "alter-ativistas" dos anos $2010^{2}$ : a busca de si, a relevância dada à dimensão humana e a consideração da "dimensão afetiva e da pessoa humana enquanto tal" (FOLLMANN, 1994, p. 492). Como resume Löwy, "sem a existência dessa cultura cristã contestatória, pregando a auto-organização e a autoemancipação dos povos, é pouco provável que o PT tivesse conseguido sobretudo ganhar tão rápido tal influência” (1987, p. 24).

Os católicos progressistas tiveram, também, importante papel de liderança no desenvolvimento da perspectiva da economia solidária no Brasil. Ao longo dos anos 1990, comunidades cristãs e padres comprometidos estimularam inúmeros projetos de economia solidária em nível local, que são referências nessa área até hoje (GUERRA, 2017, p. 88). Os "projetos alternativos comunitários" dos vários atores do cristianismo da libertação foram os precursores e, posteriormente, os atores do vigoroso movimento de economia solidária que o país conheceu nos anos 2000 (GOMES et al., 2012; SINGER, 2002). Do mesmo modo, eles tiveram papel central na criação e na organização do Fórum Social Mundial, o qual teve quatro de suas cinco edições iniciais realizadas em Porto Alegre (WHITAKER, 2006). Nas últimas 
décadas, os teólogos da libertação brasileiros, principalmente Leonardo Boff, contribuíram para a renovação de uma teologia ecológica, a qual influenciou fortemente a encíclica Laudato Si do Papa Francisco (2014).

O cristianismo da libertação produziu seus principais impactos sociais e políticos nos anos 2000, duas décadas após a mudança de rumo determinada pelo Vaticano. Poderíamos, então, pensar que os ataques de Roma à Teologia da Libertação tiveram impacto apenas limitado e que o cristianismo da libertação possuía bases suficientemente sólidas para neutralizar os sucessivos ataques. Ocorreu o contrário. O impacto da mudança na Igreja e o declínio do cristianismo da libertação tiveram consequências dramáticas, que apenas foram reveladas três décadas depois, nos anos 2010.

\section{A Virada Conservadora no Vaticano}

O enfraquecimento do cristianismo da libertação brasileiro tem múltiplas razões, desde a dinâmica interna das CEB até as ambiguidades do processo de democratização do país. Contudo, não é um fenômeno essencialmente brasileiro. O enfraquecimento do cristianismo da libertação é um fenômeno global e tem uma de suas principais raízes no giro conservador do Vaticano.

A retomada do Vaticano pelos conservadores começou no fim dos anos 1960, quando membros progressistas da conferência foram privados de meios de ação (HOUTART, 2018) e progressivamente substituídos por bispos conservadores. No entanto, foi com o pontificado de João Paulo II que o giro conservador ganhou força (DUSSEL, 1990). O papa polonês associou os interesses, apresentados por adeptos da Teologia da Libertação, pelas análises marxistas à opressão do regime comunista ateu em seu país de origem. Os ataques contra a Teologia da Libertação e as CEB foram orquestrados pelo Vaticano e aconteceram em quatro frentes.

A primeira frente foi a da teologia. Em 1983, o novo chefe da Congregação para Doutrina da Fé, cardeal Josef Ratzinger, futuro Papa Bento XVI, publicou uma nota chamada "Dez observações sobre teologia de Gustavo Gutiérrez" ${ }^{3}$. No ano seguinte, na "Instrução em certos aspectos da Teologia da Libertação", ele alertou sobre os riscos de novas heresias e desvios associados ao contato com a ideologia marxista (COMPAGNON, 2006). Um terceiro texto foi publicado em 1985:

"Sobre liberdade e liberação cristã". Embora, nesse documento, as críticas fossem mais moderadas, inclusive ressaltando alguns aspectos da Teologia da Libertação, como a atenção dedicada aos pobres, o texto tratava dessa questão apenas como espiritual, retirando do contexto sócio-revolucionário (Löwy, 1997, p. 73).

A segunda frente de ataques foi a repressão dos adeptos ao movimento da Teologia da Libertação, com a imposição de sanções aos padres católicos mais críticos. Um exemplo foi o teólogo brasileiro Leonardo Boff, sentenciado a "um ano de silêncio" e mais uma série de punições, até ser levado a renunciar ao sacerdócio em 1992.

A terceira frente de repressão, que teve o impacto mais forte nos grupos progressistas da igreja brasileira, foi uma sistemática nomeação de bispos conservadores para ocupar o lugar dos progressistas que se aposentavam. Isso incluiu a nomeação de um bispo da Opus Dei muito conservador.

Por fim, na quarta frente, esses ataques contra os progressistas católicos foram combinados com um crescente apoio a perspectivas, grupos e rituais conservadores. O Vaticano e a nova hierarquia da Igreja Católica brasileira estimulavam correntes religiosas baseadas numa religiosidade emocional 
em vez do compromisso social. Um exemplo é o movimento espiritual católico chamado Renovação Carismática, no qual ritos, cerimônias e eventos religiosos são, em muitos aspectos, similares aos das igrejas pentecostais, além de ser dada demasiada importância a questões morais associadas à sexualidade, enquanto se desdenham as causas sociais.

Como Junqueira (2017a) nos lembra, "ideologia de gênero" é uma invenção católica que emergiu em meados dos anos 1990 no Conselho Pontifício Para a Família e na Congregação para a Doutrina da Fé. Em 1997, o cardeal Ratzinger publicou um livro intitulado $A$ agenda de gênero, que segue sendo referência para fundamentalistas católicos e neopentecostais. Sob essa invenção, tais fundamentalistas encaixam as demandas feministas e LGBT, em particular no que diz respeito a aborto, mobilizações a favor do casamento entre pessoas do mesmo sexo e campanhas contra a homofobia.

No fim, a virada conservadora da Igreja Católica, nos anos 1980, teve um efeito devastador sobre a Teologia da Libertação no Brasil e na América Latina. Se, quinze anos antes, a Teologia da Libertação dominava as conferências dos bispos brasileiros e latino-americanos, ela acabou reduzida a ser, nas palavras de um de seus observadores e participantes ativos, o cânone Houtart, "institucionalmente semiclandestina" (2006, p. 32).

\section{O Avanço dos Evangélicos Neopentecostais}

\section{A Chegada dos Novos Evangélicos}

Um dos resultados diretos dos ataques contra a Teologia da Libertação e as CEB foi a gradual, mas incontrolável, perda dos espaços das Igrejas Católicas nas favelas e nos subúrbios, onde mora a classe trabalhadora. Isso teve uma dupla consequência. Primeiro, houve uma diminuição substancial e, em alguns casos, uma eliminação de uma das principais fontes de ativismo progressista, dado que as CEB serviam como espaços de educação popular e encontro de comitês de cidadãos. Em segundo lugar, criou-se um vácuo nos bairros populares, abandonados pela Igreja Católica, o qual foi massivamente preenchido pelas igrejas neopentecostais conservadoras (DIVINO NUNES, 2006). Inclusive, nos anos 1980 e 1990, o neopentecostalismo foi um fenômeno principalmente urbano, com forte investimento das novas igrejas nas favelas e regiões periféricas. Da mesma forma, por causa das rápidas adaptação e descentralização, os neopentecostais conseguiam abrir igrejas em novas e, por vezes, informais localidades que se formavam graças ao rápido processo de urbanização que o Brasil viveu naquela época. Por outro lado, a hierarquia católica sofreu com uma organização logística mais pesada e lenta, combinada com a desconfiança de muitos padres comprometidos com a comunidade e suspeitos de serem próximos à Teologia da Libertação.

Nesses locais, as igrejas neopentecostais assumiram a missão da educação popular nas favelas e se tornaram incubadoras de pequenos empreendedores e militantes conservadores, cuja visão religiosa levava a defender a questão moral e, em particular, a moral associada à sexualidade (aborto, casamento, homossexualidade etc.).

\section{A Diversidade dos Evangélicos}

Para entender o protagonismo de alguns setores evangélicos na política brasileira e sua evolução nas últimas décadas, é preciso superar problemas analíticos presentes em muitos relatos e análises sobre a crescente influência dos evangélicos na vida política. 
Primeiramente, é indispensável questionar a relevância "dos evangélicos" como unidade de análise e desconstruí-los como categoria analítica quanto à agência dos fiéis das igrejas evangélicas na política contemporânea. Na maior parte da ampla bibliografia sobre esse tema, produzida nos últimos anos, os evangélicos são tratados como uma unidade analítica, indicando, por exemplo, quantos evangélicos participam em cada partido político ou como sua opinião difere da opinião dos católicos. Esses estudos demonstram a heterogeneidade política dos evangélicos, que reflete sua heterogeneidade religiosa e teológica. Tal heterogeneidade interna aponta a irrelevância da categoria geral "evangélicos" nas análises políticas contemporâneas. O aspecto relevante não é a adesão ao catolicismo ou a uma igreja evangélica, mas as correntes conservadoras e progressistas dentro do catolicismo e do evangelismo. Assim, nem todos os evangélicos são conservadores. Os fiéis luteranos, metodistas e presbiterianos formam a maioria dos "evangélicos históricos", como costumam ser chamados, e se envolveram na Teologia da Libertação em proporção similar aos católicos, não tendo se juntado aos parlamentares conservadores da frente evangélica.

O segundo aspecto é que a batalha em curso não opõe católicos e evangélicos, mas movimentos sociais entendidos como atores históricos que têm uma visão de mundo e disputam as orientações culturais de uma sociedade (TOURAINE, 1981). O cristianismo da libertação não é uma corrente unicamente católica. Está presente em diversas religiões e, em particular, entre muitas igrejas evangélicas na América Latina. No Brasil, muitos evangélicos foram atores importantes a utilizá-lo (Löwy, 1997, capítulo 8). À frente deles, revigorou-se um movimento religioso reacionário que não se limita às igrejas neopentecostais ou evangélicas. Os conservadores católicos, tanto no Brasil quanto no Vaticano, jogaram papel decisivo na reconfiguração e no crescimento desse movimento, por exemplo com os ataques à "ideologia de gênero".

Em terceiro lugar, além de diferentes orientações políticas e culturais, que coexistem entre os evangélicos, é preciso dar conta da diversidade de suas relações com a sociedade mundana e a política, assim como sua evolução ao longo do tempo. Nem todos os evangélicos buscam ser protagonistas do cenário político e separam o político do religioso. Para além disso, historicamente, a maioria dos evangélicos rechaçou explicitamente o mundo e a política, motivada por uma ética ascética e puritana orientada para a conquista da salvação extramundana (ALGRANTI, 2010).

Adicionalmente, se existe no Brasil uma forte tendência de alguns setores evangélicos de votar em seus correligionários, tal voto confessional não é uma variável explicativa, mas o resultado construído pelos atores que mudaram a relação de seus fiéis entre fé e política. De fato, como explica Pérez Guadalupe, o voto confessional de setores evangélicos "funciona no Brasil enquanto no resto dos países da região seria mais difícil” (2018). No Brasil também essa tendência não existiu sempre: "nas últimas décadas se consolidou na cultura evangélica brasileira uma forte tradição de votar por partidos evangélicos e por evangélicos que não necessariamente estão em partidos políticos evangélicos" (PÉREZ GUADALUPE, 2018).

Finalmente, a mudança fundamental do protagonismo de alguns setores evangélicos no cenário político brasileiro (e em outros países) não vem tanto do crescimento numérico das igrejas neopentecostais, mas de uma mudança escatológica. A partir da década de 1990, surgiram, no Brasil e na América Latina, novas interpretações das escrituras, que impulsionaram uma mudança radial na atitude de certos cristãos no mundo e na política. Quando o protestantismo os convidou a fugir dos valores mundanos de modo a conquistar sua salvação, as interpretações das escrituras ganharam força. Primeiramente, com a Teologia da Prosperidade, os fiéis foram instigados a recusar os valores mundanos e ver os sinais da bendição divina e da recompensa pelos seus atos virtuosos (e cumprir o pagamento 
do dízimo na igreja). Em segundo lugar, a "Teoria do Reino" os convidou a "trabalhar ativamente para a restauração do reino de Deus na terra” (PÉREZ GUADALUPE, 2018, p. 38; ALGRANTI, 2010). Os fieis deveriam contribuir para uma transformação da sociedade em seu conjunto, não somente da comunidade de crentes, como é o caso das comunidades evangélicas históricas. Plano de Poder: Deus, os Cristãos e a Política, publicado em 2008 pelo fundador e bispo da Igreja Universal do Reino de Deus, Edir Macedo, faz parte dessa perspectiva, que teve protagonismo maior na política brasileira na década seguinte.

\section{O Êxito Político dos Neopentecostais no Brasil}

Nas últimas duas décadas do século XX, os neopentecostais gradualmente investiram na esfera pública. Seus membros se envolveram com partidos políticos (MACHADO; BURITY, 2014). Em 1986, doze neopentecostais foram eleitos para o Congresso Federal. Eles fizeram campanha ao lado de católicos conservadores em torno de causas comuns, como a oposição ao aborto e às demandas do movimento feminista (CARRANZA; VITAL DA CUNHA, 2018).

Se, agora, políticos reacionários acusam o PT de todos os pecados, ao longo dos governos petistas (2002-2015), todos ficaram bem acomodados, negociaram apoio a algumas leis propostas pelos presidentes e tiveram um crescimento e ganho de influências consideráveis. Como lembra Almeida (2019), a Igreja Universal, primeiramente por meio do Partido Liberal (PL) e, depois, pelo Partido Republicano Brasileiro (PRB), entrou no governo petista em 2003 e lá permaneceu até poucas semanas antes do impeachment da presidenta Dilma Roussef. Marcello Crivella foi Ministro da Pesca e Aquicultura entre 2012 e 2014. Em 2003 foi formada a Frente Parlamentar Evangélica, que reuniu diversos deputados e senadores de várias igrejas neopentecostais abrigados sob a legenda de vários partidos. No início da legislatura de 2014-2018, eles contabilizavam 69 deputados e senadores, número que cresceu para 90 em setembro de 2016 e para quase 120 após as eleições de 2018.

Alguns analistas, como Pérez Guadalupe (2018), destacam o "pragmatismo" da "bancada evangélica", que não tem problema em negociar favores tanto com a "bancada ruralista", para obter concessões a rádios evangélicas, quanto com o governo petista. O governo precisava, regularmente, dos votos da "bancada evangélica" para aprovar projetos considerados cruciais pelo PT, o qual, em contrapartida, cedeu em questões consideradas menos importantes, mas entre as quais estava a agenda neopentecostal. Como resumido pela pesquisadora e ativista feminista Mattos, "Lula e Dilma usaram a questão de gênero como moeda para negociar com os conservadores. Eles abriram mão de políticas públicas de gênero para manter o apoio dos evangélicos em outras áreas” (2019).

No início da década de 2010, a frente evangélica teve mais sucesso do que qualquer outra força política, tirando vantagem do período caracterizado pelo declínio da influência do PT, que enfrentou crescentes dificuldades políticas para a aprovação de leis e mesmo para a manutenção de suas questões e suas visões no centro dos debates públicos e da agenda política.

Entre os maiores ganhos dos neopentecostais está a nomeação de Marco Feliciano, um pastor evangélico, para a Comissão de Direitos Humanos e Minorias da Câmara dos Deputados, em 2013, apesar de suas declarações públicas homofóbicas e de processos judiciais em curso. Outra vitória da "bancada evangélica" foi a retirada de uma cartilha anti-homofobia das escolas públicas, em maio de 2011. Parlamentares evangélicos conservadores linha-dura e católicos atuaram para bloquear as políticas econômicas e sociais do governo enquanto a cartilha fosse distribuída nas escolas públicas. Apesar de a 
cartilha ter sido aprovada como material educacional, de ter sido impressa e de ser uma das promessas de campanha de Dilma Rousseff ao movimento LGBT, a presidenta acabou cedendo à intensa pressão. Além das vitórias legislativas mais notórias da "bancada evangélica", Carranza e Cunha apontam para:

os inúmeros projetos de lei e de emendas parlamentares formuladas por evangélicos. Esses projetos não indicavam sua força política em termos de efetividade em aprovar tudo ou parte de suas propostas, mas um modo de ação baseado na produção de "fatos políticos", e a colocação dos seus temas relacionados ao "Reino" no centro do debate público (2018, p. 489).

A eleição do bispo evangélico conservador Marcelo Crivella para a Prefeitura do Rio de Janeiro, em 2016, indicou a ocorrência de mudanças, além de mostrar que a influência das igrejas neopentecostais havia crescido. Dois anos depois, 55,13\% dos votos dos brasileiros foram dados a Jair Bolsonaro, católico batizado no Jordão por um pastor neopentecostal (OUMALOU, 2019) e que tinha como slogan de campanha "Brasil acima de tudo. Deus acima de todos". Tal candidato intitulou seu programa de governo de "Caminho para a Prosperidade", numa referência direta à Teologia da Prosperidade, importante para os pastores neopentecostais.

Durante toda a campanha eleitoral, o candidato de extrema-direita pôde contar com as redes sociais, bem como com a experiência e o apoio material das igrejas conservadoras, inclusive aquele que era, então, o terceiro maior (hoje segundo) canal de televisão do Brasil, a TV Recor ${ }^{4}$. A emissora faz parte de um conglomerado pertencente ao fundador e líder da maior igreja neopentecostal no Brasil, o já citado bispo Edir Macedo, da Igreja Universal do Reino de Deus.

A preeminência alcançada pelos conservadores e seus partidários teve implicação na vida política dos evangélicos, o que ficou evidente nas eleições de 2018. Jair Bolsonaro obteve 11 milhões de votos a mais do que Fernando Haddad, candidato do PT a presidente, entre os evangélicos. Sem dúvida, as análises disponíveis dos votos (OUALALOU, 2019; ALMEIDA, 2019) reiteram que as frentes de batalha política e cultural em jogo no Brasil não opõem evangélicos e católicos. Esses últimos votaram em número praticamente igual em Bolsonaro (29,8 milhões) e Haddad (29,6 milhões), contribuindo para a vitória do primeiro.

\section{Uma Influência Cultural}

A conquista da presidência da república é auge de um projeto iniciado no começo dos anos 1980. Isso prova que movimentos religiosos estão entre os poucos movimentos sociais capazes de desenvolver um projeto ao longo de várias décadas. No entanto, muitos líderes neopentecostais veem a eleição de Jair Bolsonaro apenas como o começo do caminho para implementação de sua visão de mundo reacionária. Para isso, contam não apenas com o presidente, mas também com a Frente Evangélica no Congresso Nacional; com prefeitos e governadores espalhados em cidades e estados do país; e com canais de televisão.

Além do sucesso eleitoral, as igrejas neopentecostais também se tornaram fonte de militantes para movimentos reacionários, como a Escola Sem Partido (FRIGOTTO, 2017), que acusa professores de esquerda de tirarem vantagem de sua posição com relação aos alunos para disseminar o comunismo ou a "ideologia de gênero". 
Assim como a Teologia da Libertação era uma incubadora de movimentos progressistas, os movimentos reacionários de hoje em dia têm seu caminho nas igrejas neopentecostais.

\section{A Guerra dos Deuses}

Nas últimas quatro décadas, o Brasil tem sido um dos principais campos de batalha de uma "guerra dos deuses". Os campos em confronto nessa batalha não seguem os limites das religiões oficiais. Não se trata de uma competição entre católicos e evangélicos buscando atrair o máximo de fiéis no país, que continua, aliás, sendo o mais católico do planeta. A batalha é entre um conjunto de visões progressistas do cristianismo, realizadas por católicos e protestantes que colocam as questões sociais no âmago de seu compromisso, e visões conservadoras, para as quais os assuntos morais, principalmente relacionados à sexualidade (homossexualidade, aborto, divórcio) estão no centro do compromisso cristão.

Essas duas correntes têm visões de mundo e convicções religiosas radicalmente opostas. Os primeiros apelam a uma vida humilde e são críticos do capitalismo e de certas dimensões da modernidade (MARTÍNEZ ANDRADE, 2015). Ao contrário, a Teologia da Prosperidade, defendida pelos segundos, apoia o capitalismo neoliberal e convida a ver no sucesso econômico uma recompensa divina pela probidade moral e pela devoção a Deus e à sua igreja, incluindo orações e pagamento do dízimo.

Entretanto, atores do cristianismo da libertação e neopentecostais compartilham visões muito semelhantes com relação ao papel que a religião deve desempenhar na transformação da sociedade. Acreditam que a fé não pode ser confinada à esfera privada, mas deve se envolver nessa transformação. Esses atores investem, portanto, em espaços sociais e arenas políticas a fim de realizar suas ações e implementar sua visão de mundo. Ambas as correntes se envolvem massivamente nos bairros, ancoram suas práticas em seu tempo e formam o terreno fértil de uma nova cultura política.

Nas últimas duas décadas do século XX, os neopentecostais brasileiros se beneficiaram muito de uma expansão global das igrejas evangélicas americanas (BROUWER et al., 1996). Sua implementação foi facilitada por essas redes transnacionais, nas quais recursos, discursos e práticas comprovadamente atraentes para uma ampla audiência, nos Estados Unidos e em todo o mundo, circulavam. Por outro lado, os cristãos da libertação tiveram que enfrentar os ataques do Vaticano e viram sua base material e seu apoio institucional diminuírem substancialmente com a substituição de bispos progressistas por conservadores. Enquanto as igrejas evangélicas encorajavam o compromisso político de seus pastores em diferentes partidos políticos, a hierarquia católica fazia sermões e até condenava fortemente padres envolvidos em partidos políticos ou que exercessem responsabilidades políticas (COMPAGNON, 2006).

No início dos anos 1980, a luta contra o comunismo ateu não era monopólio do Vaticano. Nesse período da Guerra Fria, os atores progressistas da América Latina eram alvo da política externa norteamericana, processo que estava crescendo sob o governo Reagan. Governos e movimentos progressistas eram objeto de muitas intervenções norte-americanas. No início dos anos 1980, a Teologia da Libertação foi diretamente direcionada, como evidenciado pelo relatório escrito pelos conselheiros de Reagan em Santa Fé, em maio de 1980:

A política externa dos EUA deve começar a confrontar a Teologia da Libertação. E não apenas reagindo contra ela a posteriori [...] O papel da Igreja é crucial para o conceito de liberdade política na América Latina. Infelizmente, as forças 
marxistas-leninistas usaram a Igreja como arma política contra a propriedade privada e o sistema capitalista de produção, infiltrando na comunidade religiosa ideias mais comunistas que cristãs ${ }^{5}$.

Esse processo também foi concomitante com um período de intensa internacionalização das igrejas evangélicas americanas, que forneceram diferentes formas de apoio a igrejas neopentecostais do sul do planeta (BROUWER et al., 1996).

No século XXI, ativistas neopentecostais construíram campanhas nacionais baseadas em recursos e redes internacionais (CENTURIÓN, 2018), particularmente para combater o que chamam de "ideologia de gênero".

A expansão neopentecostal e seu sucesso eleitoral se beneficiaram das afinidades entre suas práticas e visões de mundo e a cultura política populista que passou a dominar o Brasil, produzindo-as e incorporando-as. As receitas para seduzir os eleitores são semelhantes às que provaram atrair um número crescente de fiéis: os discursos flamejantes e de intensa emoção, o papel central de um líder carismático ou o uso intensivo da mídia de massa. Os pastores evangélicos têm longa experiência em fazer campanhas eleitorais populistas em todo o mundo e dominam tais táticas muito melhor do que seus oponentes políticos.

As igrejas neopentecostais brasileiras fizeram uso extensivo da mídia desde o início, primeiro inspiradas pelos televangelistas norte-americanos e depois rapidamente adaptadas à cultura brasileira (ORO, 1992). A igreja universal do Reino de Deus, fundada em 1977 por Edir Macedo, rapidamente se baseou nos meios de comunicação de massa. Em 1990, já possuía seis estações de rádio e dois canais de televisão. Atualmente, possui o terceiro maior grupo de televisão do país.

Os cristãos progressistas também têm sua mídia, mas atribuem a elas papel radicalmente diferente. Enquanto os evangelistas usam a mídia de massa para espalhar a palavra dos líderes, reter e atrair os fiéis (ORO, 1992), os cristãos progressistas desenvolvem uma “mídia popular", que visa dar voz a atores excluídos do debate público, promover a formação do discurso público e, em muitos casos, implementar programas de educação popular (SUZINA, 2018).

As igrejas neopentecostais fizeram muito mais do que ocupar os espaços que o cristianismo da libertação gradualmente deixou nas favelas do Brasil. Elas retomaram seus papéis. Nos anos 1980, o cristianismo da libertação era uma espiritualidade que levava seus atores a se envolver no espaço público em nome de sua fé e de uma visão de mundo, sendo caldeirão de uma nova cultura política e terreno fértil de ativistas dos movimentos e partidos progressistas. Atualmente, o terreno fértil para ativistas e apoiadores de Bolsonaro é ocupado por três papéis fundamentais, encarnados pelas igrejas neopentecostais.

\section{Considerações Finais}

O sucesso de Bolsonaro no Brasil deve ser analisado em diferentes temporalidades, com dinâmicas políticas próprias aos últimos anos e outras de maior alcance. É, em parte, resultado de profundas mudanças, em longo prazo e que não se limitam somente ao caso brasileiro. As igrejas neopentecostais conservadoras estão se tornando cada vez mais populares em toda a América Latina e venceram importantes batalhas políticas no Peru e na Colômbia. Na Argentina, foram os pastores neopentecostais do Brasil que iniciaram o crescimento dessas igrejas. Portanto, é importante extrair todas as lições do caso brasileiro, tanto política quanto teoricamente. A análise da evolução da influência dos atores religiosos na esfera política no Brasil oferece três lições para a sociologia dos movimentos sociais. 
Primeiramente, o caso do Brasil demanda melhor articulação entre a sociologia das religiões e a dos movimentos sociais. A sociologia dos movimentos sociais tem sido um campo dominado pela perspectiva da secularização da sociedade. As principais revistas do campo publicaram poucos ou mesmo nenhum artigo sobre o impacto da religião nos movimentos ou atores sociais, com exceção do islamismo. Os sociólogos e cientistas políticos dos movimentos sociais têm de questionar sua perspectiva sobre a crescente secularização das sociedades modernas, que deixou cegos os atores e as dinâmicas indispensáveis para entender setores importantes dos movimentos sociais contemporâneos.

Em segundo lugar, enquanto a sociologia dos movimentos sociais há muito se concentra nos atores progressistas, deve-se prestar maior atenção aos movimentos conservadores e reacionários, bem como às interações de movimentos reacionários com progressistas (PLEYERS, 2018). O caso do Brasil destaca a importância de entender melhor a capacidade dos atores religiosos conservadores de se contrapor aos atores progressistas e realizar estratégias de longo prazo nas arenas políticas, mas também de produzir subjetividades a partir de uma visão de mundo e de comprometimento social e político.

Atualmente, nenhum ator progressista parece capaz de realizar campanhas tão eficazes com base em estratégias transnacionais, aplicadas sucessiva e metodicamente em diferentes países, como neopentecostais e católicos conservadores o fazem, por exemplo, contra o que chamam "ideologia de gênero" em diferentes países da América Latina (CENTURIÓN, 2018) e, mais recentemente, na Europa Central e Oriental (KUHAR; PATERNOTTE, 2017).

Em terceiro lugar, a extensão do impacto cultural, social e político da batalha entre cristãos progressistas e conservadores também exige ênfase mais forte no desenvolvimento de longo prazo e nas "visões de mundo" na análise de movimentos sociais, campo frequentemente focado no impacto de estratégias, mobilização de recursos e campanhas no curto prazo. As visões de mundo e a espiritualidade em que os atores encontram a fonte e as motivações de seu compromisso estão no coração do cristianismo da libertação e, atualmente, no dos militantes neopentecostais.

Essas mudanças no mundo religioso podem ter consequências políticas, como se mostrou ao longo deste artigo. Contudo, limitar as mudanças a esse campo seria, sem dúvida, um erro. Movimentos religiosos, sejam progressistas, sejam conservadores, levam a mudanças culturais profundas, que, mesmo sendo bem menos visíveis que as vitórias eleitorais, têm alcance de longo prazo na mudança de valores de uma população. Tal impacto passa pelo discurso dos atores religiosos na esfera política, mas muito mais pelo protagonismo no espaço público, no mundo sócio-econômico e nos movimentos sociais que surgem dessas tendências. Foi o caso dos diversos movimentos ligados à Teologia da Libertação nas décadas anteriores. Atualmente, é o caso das mobilizações e campanhas conservadoras que difundem não apenas suas mensagens, mas também sua visão de mundo, da política, da economia e da sociedade, seja pelos meios de comunicação de massa e pelas redes sociais, seja por iniciativas concretas no setor econômico ou associativo.

A vitória eleitoral de Bolsonaro, em 2018, é parte de um processo de profunda transformação, iniciado no início dos anos 1980 e conduzido com continuidade e inteligência, ao longo de quatro décadas, por atores religiosos conservadores. Quais são os sujeitos progressistas capazes de fazer o mesmo? O cristianismo da libertação permanece vivo no Brasil. O sucesso da $14^{\text {a }}$ reunião nacional das $\mathrm{CEB}$, que reuniu 3.300 representantes dessas organizações e 63 bispos, em janeiro de 2018, sugere que o movimento poderia experimentar uma renovação ${ }^{6}$. Entre os evangélicos progressistas, também há uma renovação, com a multiplicação de iniciativas contra os maiores problemas sociais do Brasil contemporâneo, como o racismo. No entanto, ninguém espera que os atores religiosos progressistas recuperem a influência que tinham na década de 1970 e no início da década de 1980. 
Em torno de que visões de mundo os atores progressistas serão capazes de se unir para resistir aos ataques às minorias? Quais atores ou espaços serão capazes de recuperar a tocha das CEB e do cristianismo da libertação? Qual será o caldeirão de uma nova cultura política, ancorada nas visões de mundo capazes de se tornar o terreno fértil dos militantes progressistas de amanhã?

Duas pistas parecem surgir no Brasil. Os novos movimentos feministas e interseccionais, que foram os primeiros alvos dos conservadores e trouxeram milhões de pessoas às ruas para se opor a Bolsonaro. Marielle Franco encarnou em si mesma a resistência de todas as subjetividades atacadas pelos ultraconservadores: uma mulher negra, mãe, que cresceu em uma favela do Rio de Janeiro, tinha como companheira outra mulher, era socióloga social e politicamente comprometida. Rompeu as fronteiras simbólicas entre pobreza, moralidade e acesso à política institucional. Seu assassinato, em 14 de março de 2018, indicou que os atores reacionários estão plenamente conscientes dos perigos que essa corrente pode representar para eles e que a batalha pode ser frontal com o novo poder.

A outra esperança está nas sementes plantadas pela educação e no acesso mais massivo das classes populares ao Ensino Superior nos últimos quinze anos. O movimento de "escolas para todos" mostrou o espírito crítico e cidadão, bem como a aspiração por um Brasil mais justo, transportado por parte da nova geração. Escolas e universidades também estão no centro de uma batalha para defender a democracia. O novo poder está igualmente consciente disso, como evidenciado pela tentativa de impor novas formas de controle e censura incorporadas no movimento "Escola Sem Partido" e pelas intervenções militares em 22 universidades públicas às vésperas das eleições.

\section{Notas}

1. Ver Proaño, 1977.

2. O movimento de 2013 teve origem com um grupo que se opunha ao aumento da tarifa do transporte público (Movimento Passe Livre). Na sequência de seus protestos, uniram-se a eles grupos com as orientações político-ideológicas mais diversas, entre elas redes ultraliberais e opositoras vigorosas do PT, as quais dominaram o debate público brasileiro a partir de 2015 (BRINGEL; PLEYERS, 2019).

3. Gustavo Gutiérrez é um bispo peruano cujo livro Teología de la Liberación: Perspectivas (1971) sintetizava as principais teses e argumentos teológicos do movimento social que havia emergido na América Latina nos vinte anos anteriores e que se tornou referência.

4. Intervozes (2019). Media Ownership Monitor: TV Record. Disponível em: https://brazil.mom-rsf.org/en/media/detail/outlet/record-tv-1. Acesso em: 01 jun. 2020.

5. “A New Interamerican Policy for the Eighties" (COMMITTEE OF SANTA FE, 1980, apud LÖWY, 1997, p. 99).

6. Carta dos bispos presentes no 14 Intereclesial das Comunidades Eclesiais de Base, em 27 de janeiro de 2018. Disponível em: https:// cptnacional.org.br/publicacoes/noticias/geral/4212-carta-dos-bispos-presentes-no-14-intereclesial-das-comunidades-eclesiais-de-basecebs. Acesso em: 10 jun. 2020.

\section{Referências}

ALGRANTI, J. M. Política y religión en los márgenes. Nuevas formas de participación social de las megaiglesias evangélicas en la Argentina. Buenos Aires: CICCUS, 2010. 
ALMEIDA, R. A onda quebrada. Evangélicos e conservadorismo. Cadernos Pagu, n. 50, 2017:e175001, 2017. https:// doi.org/10.1590/18094449201700500001

ALMEIDA, R. Bolsonaro presidente: Conservadorismo, evangelismo e a crise brasileira. Novos estud. CEBRAP, v. 38, n. 1, p. 185-213, 2019. https://doi.org/10.25091/s01013300201900010010

AMARAL, M. Jabuti não sobe em árvore: Como o MBL se tornou líder das manifestações pelo impeachment. In: JINKINGS, I.; DORIA, K.; CLETO, M. (coords.). Por que gritamos golpe. San Pablo: Boitempo, 2016.

BARREIRO, A. Basic Ecclesial Communities. Maryknoll: Orbis Books, 1982..

BLEIL, S. Vie et lutte des sans terres au sud du Brésil. Paris: Karthala, 2012.

BOFF, L. Church: charism and power. Liberation theology and the institutional church. New York: Wipf and Stock, 1981.

BOFF, L. Ecclesiogenesis: The base communities reinvent the church, Maryknoll: Orbis Books, 1986.

BOFF, L. Une alternative de pouvoir dans l'Église. Social Compass, v. 41, n. 4, p. 503-511, 1994.

BURDICK, J. Procurando Deus no Brasil. Petrópolis: Vozes, 1996.

BRINGEL, B. ; DOMINGUES, J. M. El asesinato de Marielle Franco y el futuro de Brasil. Brasil: Cambio de era. Madrid: Catarata, 2018.

BRINGEL, B.; PLEYERS, G. June 2013, Five years later: Polarization, reconfiguration of activism, and challenges for the Brazilian left, In: PUZONE, V.; MIGUEL, L. F. (eds.). The Brazilian Left in the 21st Century. London: Palgrave, p. 237-257, 2019.

BROUWER, S.; GIFFORD, P.; ROSE, S. Exporting the American gospel: Global christian fundamentalism. New York: Routledge, 1996.

CARRANZA, B.; VITAL DA CUNHA, C. Conservative religious activism in the Brazilian Congress: Sexual agendas in focus, Social Compass, v. 65, n. 4, p. 486-502, 2018.

CENTURIÓN, J. Género. Bajo ataque. Brazil, Costa Rica, Perú, Colombia, Lima: Centurión Producción, 2018.

COMPAGNON, O. A la recherche du temps perdu... Jean-Paul II et l’Amérique latine. In : ZAGEFKA, P. (dir.). Amérique latine 2006, La Documentation française, p.11-12, 2006. (Les études de la Documentation française.)

DATAFOLHA. Perfil e opinião dos evangélicos no Brasil. PO813906, São Paulo: Instituto Datafolha, 2016.

DIVINO NUNES, T. O crescimento das igrejas neopentecostais no Brasil: Um olhar sobre a política da Igreja Universal, Cadernos de Pesquisa do CDHIS, n. 35, p. 127-132, 2006. https://doi.org/10.14393/cdhis.vli35.503

DUSSEL, E. La politique vaticane en Amérique Latine: essai d’interprétation historicosociologique. Social Compass, v. 37, n. 2, p. 207-224, 1990. https://doi.org/10.1177/003776890037002003

ESQUIVEL, J. C.; TONIOL, R. The presence of religion in the Latin American public space. Social Compass, v. 65, n. 4, p. 467-485, 2018. https://doi.org/10.1177/0037768618792811

FOLLMANN J. Les catholiques et le Parti des travailleurs au Brésil. Social Compass, v. 41, n. 4, p. 483-501, 1994. https://doi.org/10.1177/003776894041004003 
PAPA FRANCESCO. Laudato Si. Rome: Librería Editrice Vaticana, 2015.

FREIRE, P. Pedagogia do oprimido. Rio de Janeiro: Paz e Terra, 1967.

FRIGOTTO, G. (org.) Escola “sem” partido. Rio de Janeiro: LPP/Uerj, 2017.

GALLETTA, R.; DOS SANTOS, B.; SAMPAIO P. Pastoral popular e política partidária. São Paulo: Paulinas, 1986.

GOMES, R.; CASTILLA, T.; BERTUCCI, J. O. La economía solidaria en América latina y el Caribe: Actores, presencia, experiencias, redes; Reflexion y desafios.. Bogotá: CELAM; DEJUSOL, 2012.

GUERRA, P. La pensée économique de l'Église catholique. In: LAVILLE, J. L. ; PLEYERS, G. ; BUCOLO, E ; CORRAGIO, J. L. (dirs.). Mouvements sociaux et économie solidaire, Paris: Desclée de Brouwer, 2017.

GUTIÉRREZ, G. Teología de la liberación: Perspectivas. Lima: Centro de Estudios y Publicaciones, 1971.

HOUTART, F. L'Histoire du CELAM ou loubli des origines. Archives de sciences sociales des religions, v. 62, n. 1, p. 93-105, 1986. https://doi.org/10.3406/assr.1986.2404

HOUTART, F. Los pontificados de Juan Pablo II y de Benedicto XVI frente a América Latina. Nueva sociedad, p. 32-41, 2006.

HOUTART, F. The decline of certainties. Autobiography. Panama: Ruth, 2018.

JUNQUEIRA, R. "Ideologia de gênero": A gênese de uma categoria política reacionária”. In: RIBEIRO, P. R. C. R.; MAGALHÃES, J. C. (orgs.). Debates contemporâneos sobre Educação para a sexualidade. Rio Grande: Editora da FURG, p. 25-52, 2017a.

JUNQUEIRA, R. "Ideologia de gênero": Um dispositivo retórico de uma ofensiva antifeminista. In: DIAS, A. F.; SANTOS, E. F.; CRUZ, M. H. S. (orgs.). Gênero e sexualidades: Entre invenções e desarticulações. Aracaju: Editora IFS, p. 47-61, 2017b.

KOWARICK, L. Movimentos urbanos no Brasil contemporâneo: Uma análise da literatura, 1986. Disponível em: https://edisciplinas.usp.br/mod/resource/view.php?id=19018. Acesso em: 01 jun. 2020

KUHAR, R.; PATERNOTTE, D. Anti-gender campaigns in Europe. London: Rowman \& Littlefield, 2017.

LÖWY, M. A new type of party: The Brazilian PT. Latin American Perspective, v. 55, p. 453-464, 1987.

LÖWY, M. La guerre des dieux. Paris: Editions du Félin, 1997.

MACEDO, E. Plano de poder: Deus, os cristãos e a política. Rio de Janeiro: Nelson, 2008.

MACHADO, M. D.; BURITY, J. A Ascensão Política dos Pentecostais no Brasil na Avaliação de Líderes Religiosos. Dados, v. 57, n. 3, p. 601-631, 2014. https://doi.org/10.1590/00115258201419

MARTÍNEZ ANDRADE, L. Las dudas de Dios. Teología de la liberación, Ecología y Movimientos Sociales. Santander: Textos (in)surgentes, 2015.

MATTOS, A. Discursos ultraconservadores e o truque da "ideologia de gênero": Gênero e sexualidades em disputa na educação. Revista de Psicologia Política, v. 17, p. 542-551, 2019. 
MENEZES NETO, A. J. A Igreja Católica e os movimentos sociais do campo. Caderno CRH, Salvador, v. 20, n. 50, p. 331-341, 2007. https://doi.org/10.1590/S0103-49792007000200010

ORO, I. J. Religions pentecôtistes et moyens de communication de masse au Brésil. Social Compass, v. 39, n. 2-3, p. 423-434 1992. https://doi.org/10.1177/003776892039003007

OUMALOU, L. Los evangélicos y el hermano Bolsonaro, Nueva Sociedad, n. 280, p. 69-77, mar.-abr. 2019.

PÉREZ GUADALUPE, J. L.; GRUNDBERGER, S. (coords.). Evangélicos y poder en América Latina. Lima: Instituto de Estudios Social Cristianos, 2018.

PLEYERS, G. Movimientos sociales en el siglo XXI. Buenos Aires: CLACSO, 2018.

PROAÑO, L. Creo en el hombre y en la comunidad. Quito: Corporación editorial nacional, 1977.

SADER, E. Quando novos personagens entraram em cena. Experiências e lutas dos trabalhadores da grande São Paulo 1970-1980. São Paulo: Paz e terra, 1988.

SINGER, P. Introdução à Economia solidária. São Paulo: Perseu Abramo, 2002.

SINGER, P.; BRANT, V. C. (eds.). São Paulo: O povo em movimiento. Petrópolis, Vozes, 1980.

SUZINA, A. Asymmetries. Popular media initiatives and the issue of political asymmetries in the Brazilian democracy. 2018. Tese (Doutorado em Sociologia) - UCLouvain, Louvain-la-Neuve, 2018.

TORRES, C. Cristianismo y revolución. Bogotá: Era, 1970.

TOURAINE, A. The voice and the eye. Cambridge: Cambridge University Press, 1981.

WHITAKER, C. Towards a new politics: What future for the World Social Forum? New York: Zed Books, 2006.

\section{Sobre o Autor}

Geoffrey Pleyers é pesquisador dos Fonds National de la Recherche Scientifique e professor de Sociologia da Université Catholique de Louvain, na Bélgica. Vice-presidente de pesquisa da International Sociological Association. Autor dos livros Alter-Globalization. Becoming Actors in the Global Age (Cambridge, Polity, 2011) e Movimientos sociales en el siglo XXI (Buenos Aires, CLACSO, 2018). 